\title{
DETERMINATION OF THERMOMECHANICAL STRESSES IN ELEMENTS OF VEHICLES' BRAKING SYSTEMS
}

Oleksii Grevtsev ${ }^{1}$, Ninel Selivanova ${ }^{1}$, Pavlo Popovych ${ }^{2}$, Liubomyr Poberezhny ${ }^{3}$ *, Yurii Rudyak ${ }^{4}$, Oksana Shevchuk $^{2}$, Liubov Poberezhna ${ }^{3}$, Olena Skyba ${ }^{5}$, Viktor Ostroverkhov², Oleksandr Shashkevych ${ }^{2}$

${ }^{1}$ National Transport University, Kyiv, Ukraine

${ }^{2}$ West Ukrainian National University, Ternopil, Ukraine

${ }^{3}$ Ivano-Frankivsk National Technical University of Oil and Gas, Ivano-Frankivsk, Ukraine

${ }^{4}$ I. Horbachevsky Ternopil National Medical University, Ternopil, Ukraine

${ }^{5}$ Ternopil Ivan Puluj National Technical University, Ternopil, Ukraine

*E-mail of corresponding author: lubomyrpoberezhny@gmail.com

\section{Resume}

The main objective of the study was to develop a model and analyze the thermomechanical behavior of the hub material of the vehicle brake disk. The simulation strategy was based on the solution of the three-dimensional problem of the theory of elasticity for the case of effect of external loads and temperature fields on the metal structure element of the vehicle brakes. To solve this type of task of the theory of elasticity, the differential equations of the second order were used for the first time. Adaptation of the proposed model, completed in the article, has proved the correctness of use of these equations in modeling the thermomechanical processes with determination of stresses and displacements in unevenly heated rotary cylinders of the final length. The proposed method can be applied with high efficiency in stress strain state simulation of individual parts of vehicles.

Available online: https://doi.org/10.26552/com.C.2022.1.B1-B8

\section{Article info}

Received 8 February 2021

Accepted 25 May 2021

Online 30 September 2021

\section{Keywords:}

vehicles brakes, temperature change, metal structures of vehicles, theory of elasticity, brake defects and fracture, thermomechanical stress

\section{Introduction}

Frictional heat generation induces temperature gradients and thermal stresses in the contacting components of a brake. The complexity of a problem, incorporating a number of different phenomena, requires consideration at different scales. Among these scales, there are bulk, macro- and micro-levels [1-3].

Braking has a vital role in vehicle safety. In general, the braking system operates by the two main parts, the stator and the rotor. A braking system that is widely used is a friction brake, where the braking system uses the principle of friction. The rotor and the stator are creating a friction process. The brake system requires maintenance or replacement of components after a certain time. Increased life of brakes used under the large loads can be achieved by applying a layered braking system. Mechanical braking, supported with engine brakes, produces excellent braking and extends the life of the braking components [4-5].

\section{Literature review}

Based on the analysis of metal structures of vehicle elements, the dynamic loads, temperature, and environment are found to be the main factors that cause malfunctions and defects of assembly units (Figure 1). All these factors promote formation of a scale or a film on surfaces with consideration of the surfaces condition, in particular coating, roughness, hardness, etc. [6-16]. The constant influence of these factors' combinations causes damages with subsequent destruction. The most typical damages are fatigue damage, thermomechanical damage, corrosion-mechanical wear, corrosion fatigue, corrosion cracking [17-21]. Fatigue fractures cause spontaneous failure of metal structures of vehicles' components and elements, lead to weight loss, intensify wear of joints, change the amount of surface roughness of parts, reduce fatigue strength and initiate cracks. Therefore, the reliability and durability of machines and their elements are reduced and the costs of repair and elimination of the consequences of failures are increased $[16,19]$.

The metal materials of nodes and parts of vehicles are a function of mechanical and thermal stresses considered in the spatial coordinate system. In the simulation of analytical models of stress - strain state in such materials, axisymmetric problems of elasticity theory are classified as spatial ones, which hardly could be solved from the standpoint of mathematics. The solution of the axisymmetric problem should strictly 

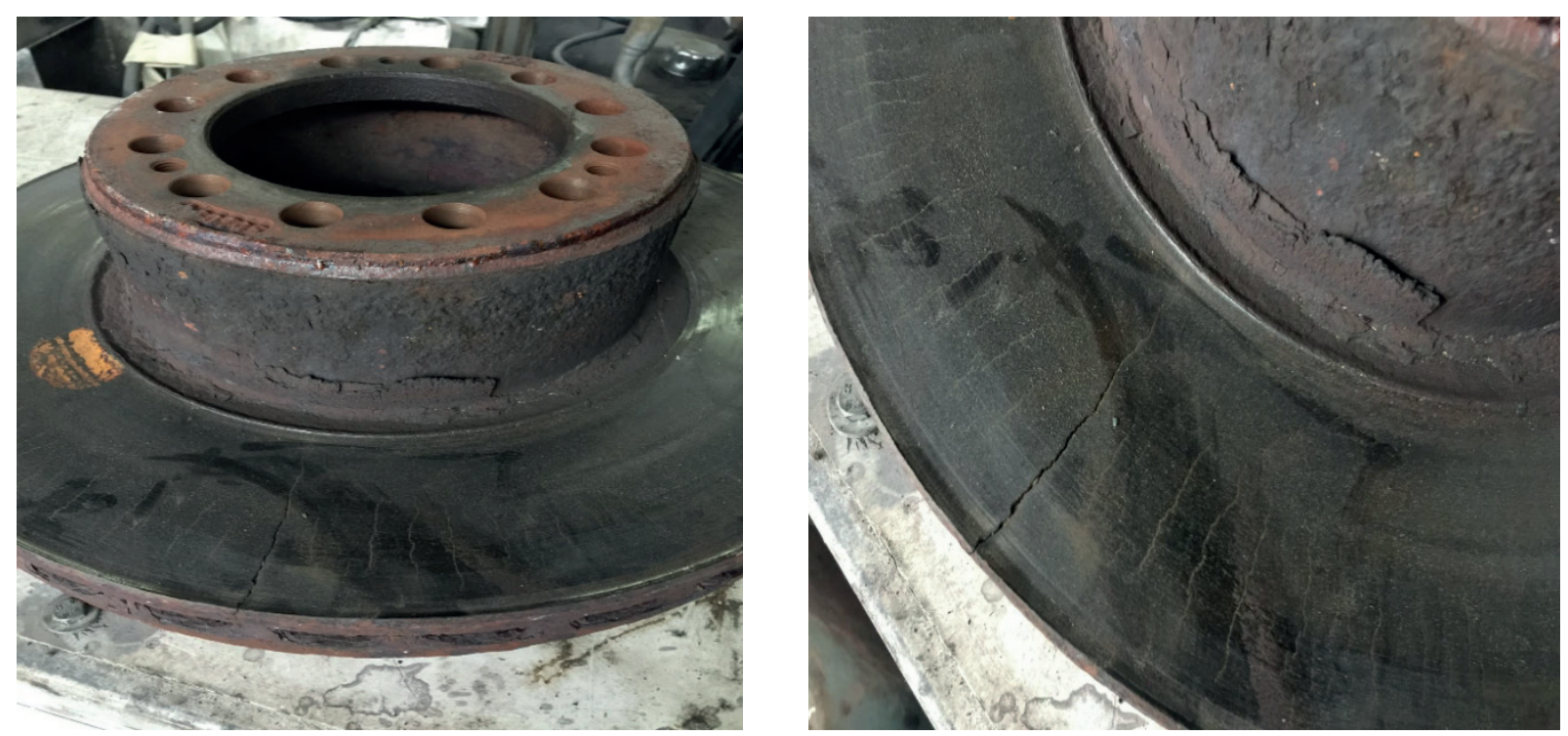

Figure 1 Defects of the brake disk of a truck

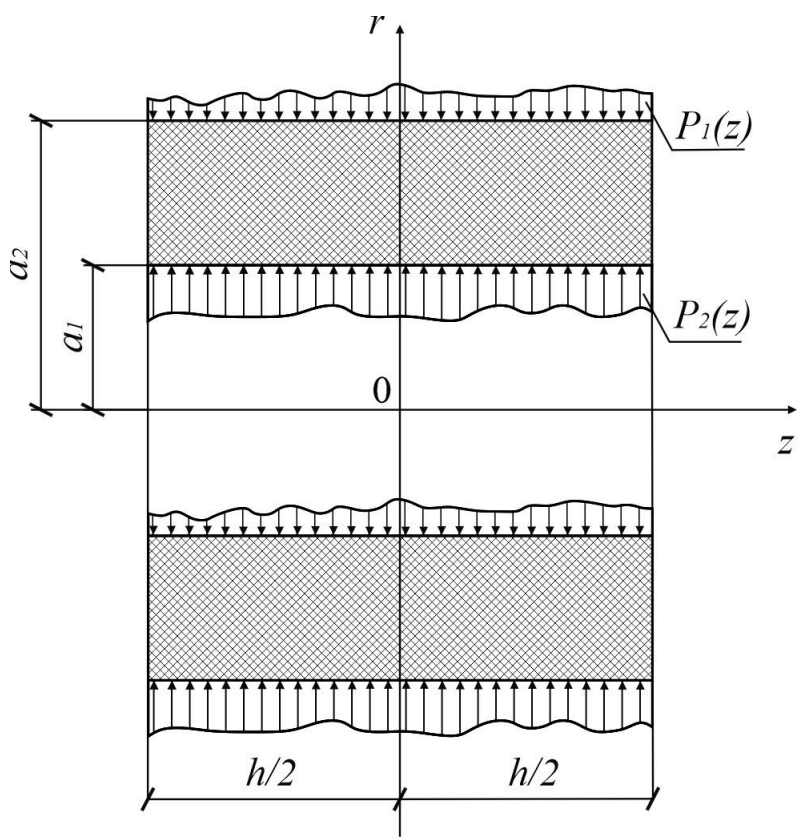

Figure 2 Analytical model of the cylinder under the action of centrifugal force

and completely satisfy all the boundary conditions on the side surfaces and ends of bodies of rotation [18]. Therefore, the decision-making of such a solution is problematic from the point of view of the elasticity theory. The problem of the stress-strain state of a cylinder of finite length can be solved by numerical methods, which leads to cumbersome constructions of many systems of linear algebraic equations, or to integral equations of the second kind [22-23]. In such equations, normal and tangential stresses are written in the form of series of special functions, which is inconvenient for practical application [24-25]. The ability to understand the processes occurring in the materials of the elements under study, without adequate recorded analytical dependencies, is limited; only the results of calculations can be analyzed. This is a disadvantage of the stress strain state simulation of the metal structures elements by means of the 3D simulation technologies [21-22, 24-25]. When the force is applied on a brake pedal, it causes the brake pads to stick with disc brake, which creates artificial friction; due to this friction rusting of rotors and pads takes place, responsible for deformation and various thermal stresses due to large increase in temperature and friction takes place. Due to these unsuitable conditions, consequences appear, like the microscopic cracks, permanent failures, thermal deformation due to frictional heating and various elastic after-effect produces on the friction surfaces of disc [26].

The main objective of this study was to develop a model and to analyze the thermomechanical behavior of the vehicle brake disk material for ensuring the required operational reliability of disc brakes. 


\section{$3 \quad$ Methodology}

To solve such problems with maximum accuracy, the provisions of the theory of elasticity should be applied; then, the adequate simulation of stresses and displacements under operating loads would be provided. It is advisable to improve the theoretical foundations for the better understanding of thermomechanical processes in rotating bodies, in particular cylindrical elements of metal structures of vehicles (brake disk hubs, etc.) that are under the simultaneous action of thermal and mechanical stresses.

A hollow cylinder of finite length $z(-h / 2 \leq z \leq h / 2)$ (Figure 2), which rotates (without bending) under the action of centrifugal force $F_{r}$, is under study.

$F_{r}=\rho \omega^{2} r$ in a temperature field $\theta=\theta(r, z)$ if $\rho$ - material density; $r$ - radial coordinate

In the cylindrical coordinate system $(r, z)$, for the considered body of rotation, the differential equations of equilibrium, written for displacements and stresses, are deduced [26-29]:

$$
\begin{aligned}
& \Delta u_{1}-\frac{u_{1}}{r^{2}}+\frac{e_{1}}{1-2 v}-2 \frac{(1+v)}{(1-2 v)} \alpha \theta_{1}=0, \\
& \Delta u_{3}+\frac{e_{3}}{1-2 v}-2 \frac{(1+v)}{(1-2 v)} \alpha \theta_{3}=0, \\
& \sigma_{11,1}+\sigma_{13,1}+\frac{\sigma_{11}-\sigma_{22}}{r}=0, \\
& \sigma_{13,1}+\sigma_{33,3}+\frac{1}{r} \sigma_{13}=0 .
\end{aligned}
$$

In Equations (1) and (2), the subscript written after the comma denotes the partial derivative by the corresponding coordinate: $r$ or $z$.

Boundary conditions on the surface of the body of rotation (model of the brake disk hub) are developed [23-24]:

$$
\begin{aligned}
& P_{r}=\sigma_{11} \cos (r, n)+\sigma_{13} \cos (r, n), \\
& P_{z}=\sigma_{13} \cos (r, n)+\sigma_{33} \cos (r, n),
\end{aligned}
$$

if $P_{r}$ and $P_{z}$ - projections of surface forces to directions $r$ and $z$, respectively; $n$ - normal to the surface of the body of rotation.

Based on the Hooke's law for the spatial theory of elasticity, stress components are determined [28]:

$\sigma_{i j}=2 G\left(e_{i j}+\frac{v}{1-2 v} e \delta_{i j}-\frac{1+v}{1-v} \alpha \theta \delta_{i j}\right)$

for $i, j=1,2,3$,

where the known dependences between the displacements and deformations remain valid:

$$
\begin{aligned}
& e_{11}=u_{1,1}, \\
& e_{22}=\frac{1}{r} u_{1}, \\
& e_{33}=u_{3,1}, \\
& 2 e_{13}=u_{1,3}+u_{3,1} .
\end{aligned}
$$

where $\delta_{i j}$ - Kronecker symbol; $\alpha$ and $v$ - respectively, coefficients of linear thermal expansion and Poisson's ratio; $e=e_{11}+e_{22}+e_{33}$ - volumetric expansion; $G=E /(1+v)$ - shear module; $E$ - modulus of elasticity; A - coefficient of linear thermal expansion.

The proposed method is based on successive approximations of solutions that satisfy the boundary conditions in Equation (3) on the side surfaces and ends of the investigated hollow cylinder of the finite length.

\section{Results}

In the first approximation the assumption is $e_{33}=u_{13}=\sigma_{33}=0$. Since, according to the condition, the cylinder is not deformed by bending, then, based on the condition $e_{33}=u_{33}=0$, the formula $u_{3}(r, z)=w(r)=0$ is derived. Since $\sigma_{13}=2 G\left(u_{1,3}+u_{3,1}\right)=0$, then $u_{1,3}=-u_{3,1}$. However, the deflection is $w(r)=0$, then

$u_{1}(r, z)=u(r)$

Next, based on the condition $e_{33}=0$, the value of $e_{33}$ is found, which was previously assumed to be zero:

$e_{33}=-\frac{v}{1-v}\left(e_{11}-e_{22}\right)+\frac{1+v}{1+v} \alpha \theta$,

for stresses:

$$
\begin{aligned}
& \sigma_{11}=\frac{2 G}{1-v}\left[u_{1}+\frac{v}{r} u-(1+v) \alpha \theta\right], \\
& \sigma_{22}=\frac{2 G}{1-v}\left[v u_{1}+\frac{1}{r} u-(1+v) \alpha \theta\right]
\end{aligned}
$$

The next assumption is $\sigma_{13} \neq 0$. The value $\sigma_{13}$ is derived from the first equation of system in Equation (2) by integrating it by $z$ in the interval from $-h / 2$ to $h / 2$, taking into account expression in Equation (8). Providing the condition of absence of tangential stresses at the ends of the cylinder under study is satisfied ( $\sigma_{13}=0$ for $z=-h / 2 ; z=h / 2$ ), then, for the temperature field of the form $\theta(r, z)=\theta_{1}(\mathrm{r})+f(z)$ after integration, the formula is deduced

$\left[\frac{1}{r}(r u)_{1}\right]=(1+v) \alpha \theta_{1,1}-\frac{1-v}{2 G} \rho \omega^{2} r$.

Based on Equation (9), the expression for displacement is:

$$
\begin{aligned}
& u(r)=\frac{1-v}{2 G} \rho \omega^{2} \frac{r^{3}}{8}+(1+v) \alpha \frac{1}{r} \int_{a 1}^{r} r \theta_{1}(r) d s+ \\
& +A_{1} \frac{r}{2}+A_{2} \frac{1}{r}
\end{aligned}
$$

where $a_{1}$ - the radius of the central hole.

Moreover, if the cylinder is solid $\left(a_{1}=0\right)$, then for the limited finite displacements $u(r), A_{2}=0$ should be accepted.

In the second approximation, $\sigma_{13} \neq 0$, and a $\sigma_{13}=\sigma_{33}=0$. Based on Equation (7), $e_{33}$ is determined by 
integrating by $z$ in the range from 0 to $z$ since according to Equation (6), $e_{33}=u_{33}$. Therefore,

$$
u_{3}(r, z)=-\frac{v z}{1-v} \frac{1}{r}(r u)_{1}+\frac{1+v}{1-v} \alpha \int_{0}^{z} \theta(r, z) d z
$$

From the condition $u_{1,3}=-u_{3,1}$, if $\sigma_{13}=0$, based on Equation (9) and Equation (11), the resulting expression of the radial displacement $u_{1}(r, z)$ is derived:

$$
u_{1}(r, z)=u(r)-\frac{z^{2}}{2}\left[(1-v) \alpha \theta_{1,1}+\frac{v}{2 G} \rho \omega^{2} r\right],
$$

where $u(r)$ - radial displacement of the median plane points $(z=0)$. Then, after consideration of Equation (11) and Equation (7), the specified value of the axial movement $u_{3}(r, z)$ is defined taking into account Equation (12), that $e_{11}+e_{22}$ :

$$
\begin{aligned}
& u_{3}(r, z)=\frac{v}{1-v} \frac{z}{r}(r u)_{1}+\frac{v}{1-v} \frac{z^{3}}{6} \times \\
& {\left[(1+v) \alpha \Delta_{1} \theta_{1}+\frac{v}{G} \rho \omega^{2}\right]+\frac{1+v}{1-v} \alpha \int_{0}^{z} \theta(r, z) d z,}
\end{aligned}
$$

if $\Delta_{1} \theta_{1}=\theta_{1,11}+\frac{1}{r} \theta_{1,1}$.

The displacements $u_{1}(r, z)$ and $u_{3}(r, z)$ are exact solutions of equilibrium equations in Equation (1) since they are identically satisfied after performing the substitution of Equations (12) and (13), taking into account expression in Equation (10). The temperature field $\theta_{1}=\theta_{1}(r)$ is found based on the solution of the differential equation $\left(\Delta_{1} \theta_{1}\right)_{1}=0$, which is integrated into the form:

$$
\theta_{1}(r)=B_{1} \frac{r^{2}}{4}+B_{2} \ln (r)+B_{3},
$$

where $B_{1}, B_{2}, B_{3}$ - arbitrary integration constants.

\section{Discussion}

Based on the Hooke's law and the displacements found, taking into account Equation (14), in which the equation $B_{2}=0$ is accepted (i.e., the temperature is assumed to be distributed along the radius of the cylinder according to the quadratic law), stresses are determined. Moreover, the test proves that the voltage values $\sigma_{13}$ and $\sigma_{33}$ are zero (everywhere) and $\sigma_{11}$ and $\sigma_{22}$ are:

$$
\begin{aligned}
& \sigma_{11}=\frac{2 G}{1-v} \times \\
& \times\left\{\begin{array}{l}
-\left(1-v^{2}\right) \alpha B_{1} \frac{r^{2}}{16}-\alpha B_{3}-\frac{1-v}{2 G} \\
\rho \omega^{2} \frac{3+v}{8} r^{2}+A_{1} \frac{1+v}{2}-A_{1} \frac{1+v}{2} \\
-\frac{z^{2}}{2}\left[\begin{array}{c}
\frac{(1+v)^{2}}{2} \alpha B_{1}+ \\
+\frac{v(1-v)}{2 G} \rho \omega^{2}
\end{array}\right]-(1+v) \alpha f(z)
\end{array}\right\},
\end{aligned}
$$

$$
\begin{aligned}
& \sigma_{12}=\frac{2 G}{1-v} \times \\
& \times\left\{\begin{array}{l}
-\left(1-v^{2}\right) \alpha B_{1} \frac{3 r^{2}}{16}-(1+v) \alpha B_{3}- \\
-\frac{v(1-v)}{2 G} \rho \omega^{2} \frac{3+v}{8} r^{2}+A_{1} \frac{1+v}{2}+ \\
+A_{2} \frac{1+v}{2}-\frac{z^{2}}{2}\left[\begin{array}{l}
\frac{(1+v)^{2}}{2} \alpha B_{1}+ \\
+\frac{v(1-v)}{2 G} \rho \omega^{2}
\end{array}\right] \\
-(1+v) \alpha f(z)
\end{array}\right\} .
\end{aligned}
$$

For an unevenly heated rotating hollow cylinder of the finite length loaded with a uniformly distributed load $P_{2}$ on the outer surface and a load $P_{1}$ on the inner surface, satisfying the boundary conditions in Equation (3), if $\sigma_{13}=\sigma_{33}=0$, and excluding from Equation (15) the expression $(1+v) \alpha f(z)$, where $f(z)$ is an arbitrary function, the stresses $\sigma_{13}$ and $\sigma_{33}$ are defined:

$$
\begin{aligned}
& \sigma_{11}=\left(\frac{E \alpha B_{r}}{16}+\frac{3+v}{8} \rho \omega^{2}\right)\left(a_{2}^{2}+a_{1}^{2}-\frac{a_{1}^{2} a_{2}^{2}}{r^{2}}-r^{2}\right)+ \\
& +\frac{P_{2} a_{2}^{2}\left(r^{2}-a_{1}^{2}\right)-P_{1} a_{1}^{2}\left(a_{2}^{2}-r^{2}\right)}{r^{2}\left(a_{2}^{2}-a_{1}^{2}\right)} \\
& \sigma_{22}=\frac{E \alpha B_{r}}{16}\left(a_{2}^{2}+a_{1}^{2}-\frac{a_{1}^{2} a_{2}^{2}}{r^{2}}-3 r^{2}\right)+\frac{3+v}{8} \rho \omega^{2} \times \\
& \left(\begin{array}{l}
a_{2}^{2}+a_{1}^{2}-\frac{a_{1}^{2} a_{2}^{2}}{r^{2}}-\frac{1+3 v}{3+v} r^{2}+ \\
+\frac{P_{2} a_{2}^{2}\left(r^{2}-a_{1}^{2}\right)-P_{1} a_{1}^{2}\left(a_{2}^{2}-r^{2}\right)}{r^{2}\left(a_{2}^{2}-a_{1}^{2}\right)}
\end{array}\right)
\end{aligned}
$$

where $a_{2}$ and $a_{1}$ - respectively, the radii of the outer and inner surfaces of the cylinder.

In addition, if in a hollow cylinder the temperature field described by Equation (14) satisfies the equation of thermal conductivity and varies along the radius by the quadratic law $\left(B_{2}=0\right)$, for its description the expression is written:

$$
\theta_{1}(r)=T_{1}+\frac{T_{2}-T_{1}}{a_{2}^{2}-a_{1}^{2}}\left(r^{2}-a_{1}^{2}\right)
$$

where $T_{1}$ and $T_{2}$ - respectively, the temperature on the inner $a_{1}$ and outer $a_{2}$ radii of the disk, then

$$
\begin{aligned}
& B_{1}=\frac{4\left(T_{2}-T_{1}\right)}{a_{2}^{2}-a_{1}^{2}}, \\
& B_{2}=T_{1}-\frac{T_{2}-T_{1}}{a_{2}^{2}-a_{1}^{2}} a_{1}^{2} .
\end{aligned}
$$

substituting $B_{1}$ from Equation (18) into Equation (16), the final stress formulas $\sigma_{11}$ and $\sigma_{22}$ are deduced:

$$
\begin{aligned}
& \sigma_{11}=\left(\frac{E \alpha}{4} \frac{T_{2}-T_{1}}{a_{2}^{2}-a_{1}^{2}}+\frac{3+v}{8} \rho \omega^{2}\right) \times \\
& \times\left(a_{2}^{2}+a_{1}^{2}-\frac{a_{1}^{2} a_{2}^{2}}{r^{2}}-r^{2}\right)+ \\
& +\frac{P_{2} a_{2}^{2}\left(r^{2}-a_{1}^{2}\right)-P_{1} a_{1}^{2}\left(a_{2}^{2}-r^{2}\right)}{r^{2}\left(a_{2}^{2}-a_{1}^{2}\right)},
\end{aligned}
$$




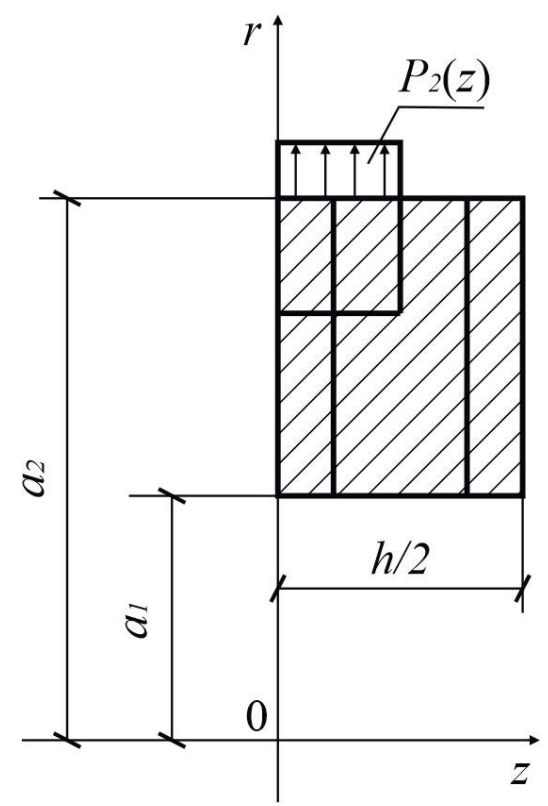

Figure 3 Analytical model of a site of the cylinder under study

$$
\begin{aligned}
& \sigma_{22}=\frac{E \alpha}{4} \frac{T_{2}-T_{1}}{a_{2}^{2}-a_{1}^{2}}\left(a_{2}^{2}+a_{1}^{2}-\frac{a_{1}^{2} a_{2}^{2}}{r^{2}}-3 r^{2}\right)+ \\
& +\frac{3+v}{8} \rho \omega^{2}\left(\begin{array}{l}
a_{2}^{2}+a_{1}^{2}-\frac{a_{1}^{2} a_{2}^{2}}{r^{2}}-\frac{1+3 v}{3+v} r^{2}+ \\
+\frac{P_{2} a_{2}^{2}\left(r^{2}-a_{1}^{2}\right)-P_{1} a_{1}^{2}\left(a_{2}^{2}-r^{2}\right)}{r^{2}\left(a_{2}^{2}-a_{1}^{2}\right)}
\end{array}\right) .
\end{aligned}
$$

Providing that $\left(P_{1}=P_{2}=0\right)$, Equation (19) is deduced:

$$
\begin{aligned}
& \sigma_{11}=\frac{E \alpha}{4} \frac{T_{2}-T_{1}}{a_{2}^{2}-a_{1}^{2}}\left(a_{2}^{2}+a_{1}^{2}-\frac{a_{1}^{2} a_{2}^{2}}{r^{2}}-r^{2}\right)+ \\
& +\frac{3+v}{8} \rho \omega^{2}\left(a_{2}^{2}+a_{1}^{2}-\frac{a_{1}^{2} a_{2}^{2}}{r^{2}}-r^{2}\right), \\
& \sigma_{22}=\frac{E \alpha}{4} \frac{T_{2}-T_{1}}{a_{2}^{2}-a_{1}^{2}}\left(a_{2}^{2}+a_{1}^{2}-\frac{a_{1}^{2} a_{2}^{2}}{r^{2}}-3 r^{2}\right)+ \\
& +\frac{3+v}{8} \rho \omega^{2}\left(a_{2}^{2}+a_{1}^{2}-\frac{a_{1}^{2} a_{2}^{2}}{r^{2}}-\frac{1+3 v}{3+v} r^{2}\right) .
\end{aligned}
$$

For a solid non-uniformly heated cylinder of the finite length, which is loaded on the outer surface by a uniformly distributed load $P_{2}\left(a_{1}=0\right)$, the formulas are developed:

$$
\begin{aligned}
& \sigma_{11}=\frac{E \alpha}{4} \frac{T_{2}-T_{1}}{a_{2}^{2}}\left(a_{2}^{2}-r^{2}\right)+\frac{3+v}{8} \rho \omega^{2} \times \\
& \times\left(a_{2}^{2}-r^{2}\right)+P_{2}, \\
& \sigma_{22}=\frac{E \alpha}{4} \frac{T_{2}-T_{1}}{a_{2}^{2}-a_{1}^{2}}\left(a_{2}^{2}-3 r^{2}\right)+\frac{3+v}{8} \rho \omega^{2} \times \\
& \times\left(a_{2}^{2}-\frac{1+3 v}{3+v} r^{2}\right)+P_{2} .
\end{aligned}
$$

Accordingly, based on the law in Equation (17), for a solid cylinder of the finite length, unevenly heated along the radius, in the absence of load, but in the presence of a temperature, the formulas are deduced:

$$
\begin{aligned}
& \sigma_{11}=\frac{E \alpha}{4} \frac{T_{2}-T_{1}}{a_{2}^{2}}\left(a_{2}^{2}-r^{2}\right)+\frac{3+v}{8}\left(a_{2}^{2}-r^{2}\right), \\
& \sigma_{22}=\frac{E \alpha}{4} \frac{T_{2}-T_{1}}{a_{2}^{2}-a_{1}^{2}}\left(a_{2}^{2}-3 r^{2}\right)+\frac{3+v}{8} \rho \omega^{2} \times \\
& \times\left(a_{2}^{2}-\frac{1+3 v}{3+v} r^{2}\right) .
\end{aligned}
$$

Equations (19) - (22) are used in the courses of elasticity theory to determine the stresses in rotating disks of constant thickness under the quadratic law of temperature distribution along the radius. The authors have proved that these formulas are valid for cylinders of the finite length, as well.

As an example, the stress strain state of a hollow cylinder is calculated applying the proposed method, an approximate solution is given in [30]. The cylinder heated to a temperature of $500{ }^{\circ} \mathrm{C}$ is under the action of centrifugal forces and external uniformly distributed load, which is applied with a flat width $b=0.1 \mathrm{~m}$ along the ring of the cylinder. The inner $a_{1}$ and outer $a_{2}$ radii of the cylinder are equal to $0.1 \mathrm{~m}$ and $0.3 \mathrm{~m}$, respectively; cylinder length is $h=0.3 \mathrm{~m}$; material is steel 25 CrMo4 ( $E=179 \mathrm{GPa}, v=0.356)$; material density is $\rho=0.8 \cdot 10^{-4} \mathrm{~kg} / \mathrm{m}^{3}$; angular speed of rotation is $\omega=400$ $\mathrm{rad} / \mathrm{s}$; intensity of the external load $P_{2}=64 \mathrm{MPa}$.

Therefore, for the reason of axial symmetry, to determine the stress strain state, one quarter of the meridional section of the cylinder should be calculated (Figure 3).

Stresses were determined in sections I-I $(z=0.01 \mathrm{~m})$ and II-II $(z=0.138 \mathrm{~m})$ at radii $r=0.01 \mathrm{~m}, 0.15 \mathrm{~m}, 0.20 \mathrm{~m}$, $0.25 \mathrm{~m}$ and $0.30 \mathrm{~m}$. The calculation results are shown in Table 1.

Based on Equation (19), the stresses were determined in the section I-I. Based on Equation (20), the load $P_{1}=0$ was determined in the section II-II. 
Table 1 Stress-strain state of a metal cylinder

\begin{tabular}{ccccc}
\hline \multirow{2}{*}{$z, \mathrm{~m} ; r, \mathrm{~m}$} & $\sigma_{11}, \mathrm{MPa}$ & \multicolumn{2}{c}{$\sigma_{22}, \mathrm{MPa}$} \\
\cline { 2 - 5 } & 0.01 & 0.138 & 0.01 & 29 \\
\hline 0.30 & 64 & 0 & 109 & 41 \\
0.25 & 73 & 12 & 124 & 52 \\
0.20 & 74 & 20 & 142 & 68 \\
0.15 & 60 & 20 & 172 & 99 \\
0.10 & 0 & 0 & 243 & 9 \\
\hline
\end{tabular}
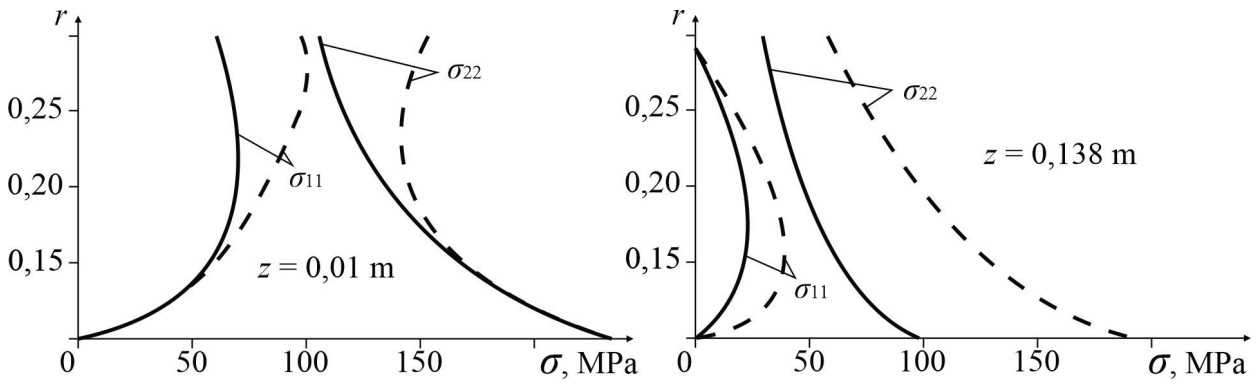

Figure 4 Graphic representations of stress dependences on radial coordinates

According to the obtained results, the developed graphical dependences of the distribution of radial and circular stresses in the sections I-I and II-II (Figure 4) are shown by solid lines. The dashed lines show the stress distribution $\sigma_{11}$ and $\sigma_{22}$ according to results of the data calculations in [21].

The graphical images were developed based on the result of calculations performed by the proposed exact method; the graphs were developed based on the results of previous calculations [21]. The comparison of such images and graphs proves that the nature of stress distribution possesses good convergence. The correctness of the analytical dependences deduced by the authors were proved. However, the values of stresses, according to the written formulas, are lower compared to similar stresses calculated in [21]. Thus, for section I-I (Figure 4), stresses at radii $r=0.10 \mathrm{~m}$ and $0.15 \mathrm{~m}$, which were found by the two methods, coincide; at a radius $r=0.20 \mathrm{~m}$, the differences are insignificant $\left(\sigma_{11}-11 \%\right.$, $\sigma_{22}-4 \%$ ), but at a radius $r=0.30 \mathrm{~m}$, they are larger $\left(\sigma_{11}-36 \%, \sigma_{22}-31 \%\right)$. In this case, to comply with the boundary conditions on the outer cylindrical surface, the value of the radial stress must be equal to the value of the external uniformly distributed load $P_{2}$, i.e., $\sigma_{11}=P_{2}=64 \mathrm{MPa}$.
In the proposed method of calculation, the given condition is fulfilled exactly $\sigma_{11}=64 \mathrm{MPa}$. In the calculation performed in [21], the accuracy is worse $\sigma_{11}=100 \mathrm{MPa}$. This is the reason for the specified difference of stresses calculated on the radius $r=0.30 \mathrm{~m}$, which is insignificant. The possibility of correct analysis of the thermomechanical behavior of the material of the brake disk hub of the vehicle is proved.

\section{Conclusions}

The exact solution and the method for determining the stresses allow to conduct a correct analysis of the thermomechanical behavior of the material of the brake disk hub of the vehicle. The study is based on the solution of a three-dimensional problem of the elasticity theory for the case of action of external loads and temperature fields on a metal structure element. An analytical study of changes in the temperature field $\theta=\theta(r, z)$ and deformation of the metal cylinder under the action of the axisymmetric load is proved that effect of such load leads to a change in the temperature field in the material with the emergence of a heat flux.

\section{References}

[1] TIROVIC, M., DAY, A. J. Disc brake interface pressure distributions. Proceedings of the Institution of Mechanical Engineers, Part D: Journal of Automobile Engineering [online]. 1991, 205(2), p. 137-146. ISSN 0954-4070, eISSN 2041-2991. Available from: https://doi.org/10.1243/PIME_PROC_1991_205_162_02

[2] DAY, A. J., TIROVIC, M., NEWCOMB, T. P. Thermal effects and pressure distributions in brakes. Proceedings of the Institution of Mechanical Engineers, Part D: Journal of Automobile Engineering [online]. 1991, 205(3), p. 199205. ISSN 0954-4070, eISSN 2041-2991. Available from: https://doi.org/10.1243/PIME_PROC_1991_205_171_02 
[3] TIROVIC, M. Development of a wheel mounted disc brake for a high-speed train. Proceedings of the Institution of Mechanical Engineers Part F Journal of Rail and Rapid Transit [online]. 1998, 212(2), p. 113-121. ISSN 0954-4097, eISSN 2041-3017. Available from: https://doi.org/10.1243/0954409981530724

[4] PUTRA, M. R. A., TJAHJANA, D. D. D. P. Fractures on braking component and relations to land-based transportation accident. Procedia Structural Integrity [online]. 2020, 27, p. 147-154. ISSN 2452-3216. Available from: https://doi.org/10.1016/j.prostr.2020.07.020

[5] BONIARDI, M., D'ERRICO, F., TAGLIABUE, C., GOTTI, G., PERRICONE, G. Failure analysis of a motorcycle brake disc. Engineering Failure Analysis [online]. 2006, 13(6), p. 933-945. ISSN 1350-6307. Available from: https://doi.org/10.1016/j.engfailanal.2005.04.012

[6] BELHOCINE, A., ABDULLAH, O. I. Design and thermomechanical finite element analysis of frictional contact mechanism on automotive disc brake assembly. Journal of Failure Analysis and Prevention [online]. 2020, 20, p. 270-301. ISSN 1547-7029. Available from: https://doi.org/10.1007/s11668-020-00831-y

[7] MAHMOUDI, T., PARVIZI, A., POURSAEIDI, E., RAHI, A. Thermo-mechanical analysis of functionally graded wheel-mounted brake disk. Journal of Mechanical Science and Technology [online]. 2015, 29, p. 4197-4204. ISSN 1738-494X, eISSN 1976-3824. Available from: https://doi.org/10.1007/s12206-015-0914-3

[8] DOROSHENKO Y., ZAPUKHLIAK, V., GRUDZ, Y., POBEREZHNY, L., HRYTSANCHUK, A., POPOVYCH, P., SHEVCHUK, O. Numerical simulation of the stress state of an erosion-worn tee of the main gas pipeline. Archives of Materials Science and Engineering [online]. 2020, 101(2), p. 63-78. ISSN 1897-2764. Available from: https://doi.org/10.5604/01.3001.0014.1192

[9] DOROSHENKO, Y., DOROSHENKO, J., ZAPUKHLIAK, V, et al. Modelling computational fluid dynamics of multiphase flows in elbow and T-junction of the main gas pipeline. Transport [online]. 2019, 34(1), p. 19-29. ISSN 1648-4142, eISSN 1648-3480. Available from: https://doi.org/10.3846/transport.2019.7441

[10] MARUSCHAK, P. O., OKIPNYI, I. B., POBEREZHNYI, L. Y., MARUSCHAK, E. V. Study of heatresistant steel strain hardening by indentation. Metallurgist [online]. 2013, 56, p. 946-951. Available from: https://doi.org/10.1007/s11015-013-9680-6

[11] POPOVYCH, P., LYASHUK, O., SHEVCHUK, O., TSON, O. P, POBEREZHNA, L. Y., BORTNYK, I. M. Influence of organic operation environment on corrosion properties of metal structure materials of vehicles. INMATEH Agricultural Engineering [online]. 2017, 52(2), p. 113-118. ISSN 2068-4215, eISSN 2068-2239. Available from: https://inmateh.eu/volumes/old-volume/volume-52-no-2-2017/article/influence-of-organic-operation-environmenton-corrosion-properties-of-metal-structure-materials-of-vehicless

[12] POPOVYCH, P., LYASHUK, O., MUROVANYI, I., DZYURA, V. O., SHEVCHUK, O. S., MYNDYUK, V. D. The service life evaluation of fertilizer spreaders undercarriages. INMATEH Agricultural Engineering [online]. 2016, 50(3), p. 39-46. ISSN 2068-4215, eISSN 2068-2239. Available from: https://inmateh.eu/volumes/old-volume/ volume-50-no-3-2016/article/the-service-life-evaluation-of-fertilizer-spreaders-undercarriages

[13] LYTVYNENKO, I. V., MARUSCHAK, P. O., LUPENKO, S. A., POPOVYCH, P. V. Modelling of the ordered surface topography of statically deformed aluminum alloy. Materials Science [online]. 2016, 52, p. 113-122. ISSN 1068-820X, eISSN 1573-885X. Available from: https://doi.org/10.1007/s11003-016-9933-1

[14] BARNA, R. A., POPOV CH, P. V. Influence of operating media on the fatigue fracture of steels for elements of agricultural machines. Materials Science [online]. 2014, 50, p. 377-380. ISSN 1068-820X, eISSN 1573-885X. Available from: https://doi.org/10.1007/s11003-014-9729-0

[15] HEVKO, B. M., DIACHUN, A. Y., LYASHUK, O. L., LIUBACHIVSKYI, R.O. The study of bulk material kinematics in a screw conveyor-mixer, INMATEH Agricultural Engineering [online]. 2015, 47(3), p. 155-162. ISSN 2068-4215, eISSN 2068-2239. Available from: https:/inmateh.eu/volumes/old-volume/volume-47-no-3-2015/ article/the-study-of-bulk-material-kinematics-in-a-screw-conveyor-mixer

[16] POPOVYCH, P., POBEREZHNY, L., SHEVCHUK, O., MUROVANYI, I., T. DOVBUSH, T., KOVAL, Y., HRYTSULIAK, H. Evaluation of strength of carrying metal structures of trailers. Journal of Achievements of Materials and Manufacturing Engineering [online] 2020, 2(100), p. 58-69. ISSN 1734-8412. Available from: https://doi.org/10.5604/01.3001.0014.3345

[17] POPOVYCH, P., SHEVCHUK, O., DZYURA, V., POBEREZHNA, L., DOZORSKYY, V., HRYTSANCHUK, A. Assessment of the influence of corrosive aggressive cargo transportation on vehicle reliability. International Journal of Engineering Research in Africa [online] 2018, 38, p. 17-25. ISSN 1663-3571, eISSN 1663-4144. Available from: https://doi.org/10.4028/www.scientific.net/JERA.38.17

[18] POPOVYCH, P. V., DZYURA, V., SHEVCHUK, O. S. Reliability estimation of transport means elements under the action of cyclic loads and corrosive environment. International Journal of Automotive and Mechanical Engineering [online] 2018, 15(4), p. 5793 -5802. ISSN 2229-8649, eISSN 2180-1606. Available from: https://doi.org/10.15282/ijame.15.4.2018.6.0443 
[19] SOKIL, B., LYASHUK, O., SOKIL, M., POPOVICH, P., VOVK, Y., PERENCHUK, O. Dynamic effect of cushion part of wheeled vehicles on their steerability. International Journal of Automotive and Mechanical Engineering [online]. 2018, 15(1), p. 4880-4892. ISSN 2229-8649, eISSN 2180-1606. Available from: https://doi.org/10.15282/ ijame.15.1.2018.1.0380

[20] POPOVYCH, P., POBEREZHNY, L., SHEVCHUK, O., MUROVANYI, I., POBEREZHNA, L., HRYTSANCHUK, A., KOVAL, Y. Corrosion-fatigue failure of tractor trailers metal materials in aggressive environments. Koroze a Ochrana Materialu [online]. 2020, 64(2), p. 45-51. eISSN 1804-1213. Available from: https://doi.org/10.2478/ kom-2020-0007

[21] JIAN, Q., SHUI, Y. Numerical and experimental analysis of transient temperature field of ventilated disc brake under the condition of hard braking. International Journal of Thermal Sciences [online]. 2017, 122, p. 115-123. ISSN 1290-0729. Available from: https://doi.org/10.1016/j.ijthermalsci.2017.08.013

[22] HAN, M. J., LEE, C. H., PARK, T. W., LEE, S. P. Low and high cycle fatigue of automotive brake discs using coupled thermo-mechanical finite element analysis under thermal loading. Journal of Mechanical Science and Technology [online]. 2018, 32(12), p. 5777-5784. ISSN 1738-494X, eISSN 1976-3824. Available from: https://doi. org/10.1007/s12206-018-1125-5

[23] THOMSEN, J. J. Vibrations and stability: advanced theory, analysis, and tools [online]. Berlin, Heidelberg: Springer Science and Business Media, 2003. ISBN 978-3-662-10793-5. Available from: https://doi.org/10.1007/978-3-66210793-5

[24] HORGAN, C. O., CHAN, A. M. The pressurized hollow cylinder or disk problem for functionally graded isotropic linearly elastic materials. Journal of Elasticity [online]. 1999, 55(1), p. 43-59. ISSN 0374-3535, eISSN 1573-2681. Available from: https://doi.org/10.1023/A:1007625401963

[25] LEPIKHIN, P. P., ROMASHCHENKO, V. A., BEINER, STOROZHUK, V. N., BABICH, Y. N., BAKHTINA, E. V. A program for numerical calculation of dynamic stress-strain state and strength of hollow multilayer anisotropic cylinders and spheres. Part 1. Program description. Strength of Materials [online]. 2015, 47(2), p. 249-256. ISSN 0039-2316, eISSN 1573-9325. Available from: https://doi.org/10.1007/s11223-015-9655-x

[26] PARKUS, H. Thermoelasticity [online]. Vienna: Springer Science and Business Media, 2012. ISBN 978-3-70918447-9. Available from: https://doi.org/10.1007/978-3-7091-8447-9

[27] KUMAR, R., NARWARIY, A. M. Failure analysis and design of disc in two wheeler. International Journal for Research in Applied Science and Engineering Technology [online]. 8(II), p. 782-789. ISSN 2321-9653. Available from: http://doi.org/10.22214/ijraset.2020.2120

[28] TYMOSHENKO, S. P., GOODIER, J. N. Theory of elasticity. New-York: McGraw - Hil, 1970. ISBN 978-0070701229.

[29] TIMOSHENKO, S. P., GERE, J. M. Theory of elastic stability. Courier Corporation, 2009. ISBN 978-0070647206.

[30] ATANACKOVIC, T. M., GURAN, A. Theory of elasticity for scientists and engineers. Boston, MA: Birkhauser, 2000. ISBN 978-1-4612-1330-7. Available from: https://doi.org/10.1007/978-1-4612-1330-7

[31] KASSNER, M. E. Fundamentals of creep in metals and alloys. Butterworth-Heinemann, 2015. ISBN 978-0080994277. 